\title{
Double ligation-assisted endoscopic submucosal resection for wider-margin resection of nonmuscularis propria subepithelial esophageal lesions
}

- Table 1 Basic patient and subepithelial lesion characteristics of three consecutive patients treated by double ligation-assisted endoscopic submucosal resection over a 2-month period.

\begin{tabular}{|c|c|c|c|c|c|c|}
\hline Age/sex & Location $^{1}$ & Size, mm & Clip closure & Complications & Histology & IHC analysis \\
\hline $45 /$ male & Distal & 7 & No & None & Leiomyoma & $\begin{array}{l}\text { Desmin + } \\
\text { CD117- }\end{array}$ \\
\hline $43 /$ male & Distal & 10 & Yes & None & $\mathrm{GCT}^{2}$ & $\begin{array}{l}\text { S-100+ } \\
\text { Desmin - } \\
\text { CD117/34- }\end{array}$ \\
\hline 69/female & Middle & 9 & Yes & None & Leiomyoma & $\begin{array}{l}\text { SMA+ } \\
\text { Desmin + } \\
\text { CD117/34- }\end{array}$ \\
\hline
\end{tabular}

Esophageal subepithelial lesions (SELs) are common in endoscopy practice. Clinical management depends on multiple factors including tissue diagnosis and, thus, assessment of malignant potential [1]. With respect to endoscopic resectability and, if appropriate, choice of therapeutic modality, characterization of the layer of origin is critical. However, as conventional low-frequency endosopic ultrasound (EUS) may not reliably determine the origin of a muscularis mucosae lesion, for example, clear-cut differentiation of the muscularis propria and nonmuscularis propria localization is more relevant. From this perspective, apart from granular cell tumors, which have a high rate of tissue diagnosis on standard forceps biopsy, EUS puncture is often discussed, but is also often technically complicated in small-sized lesions. Therefore, a more straightforward approach in easy-to-resect nonmuscularis propria lesions may be more appropriate, given adequate patient counseling and preference. Here, a novel variant technique, which is an evolution of endoscopic submucosal resection with ligation (ESMR-L) and is designated "double ligation-assisted endo-
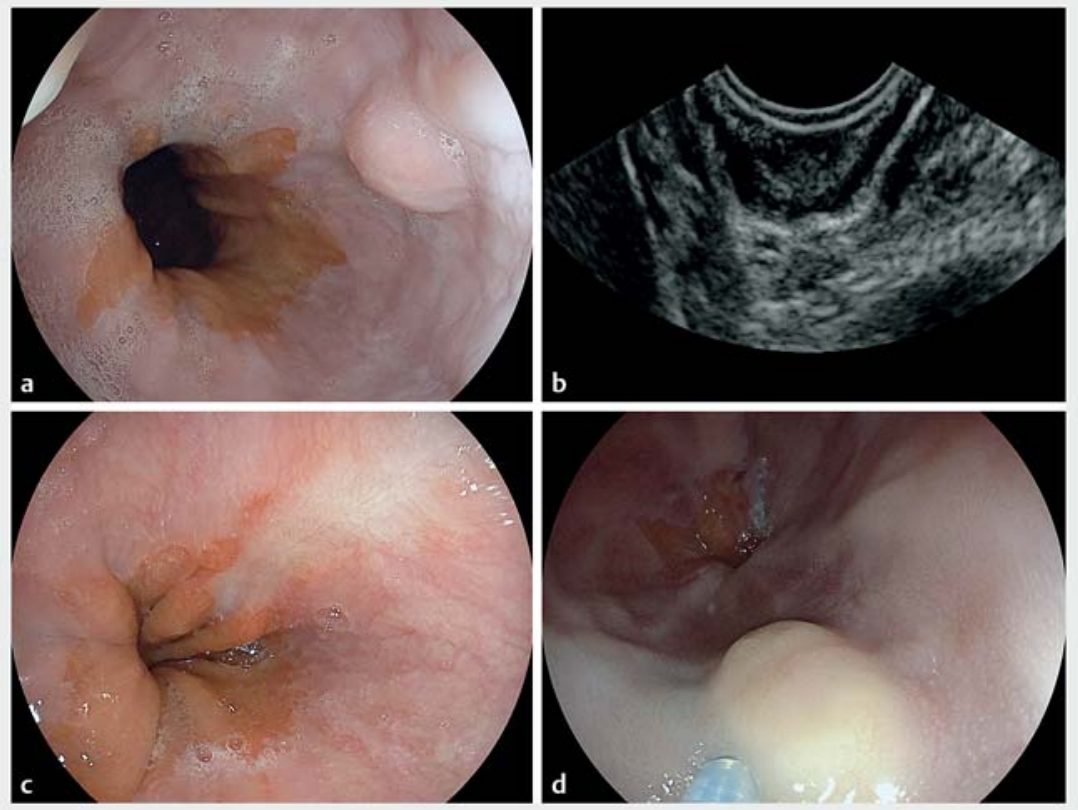

- Fig. 1 Patient 1: a An estimated 7-mm subepithelial lesion (SEL) in the distal esophagus was observed at the 2 o'clock position, with prominent luminal bulging. $\mathbf{b}$ The lesion corresponded to a hypoechoic SEL on endoscopic ultrasound, with a well-preserved muscularis propria plane. c Longitudinal post-resection scar 3 months after confirmed R0 resection. d Patient 2: yellowish, submucosal tumor in the distal esophagus at the 5 o'clock position, with a firm aspect on probing and pretherapeutic histological confirmation of a 10-mm granular cell tumor. 

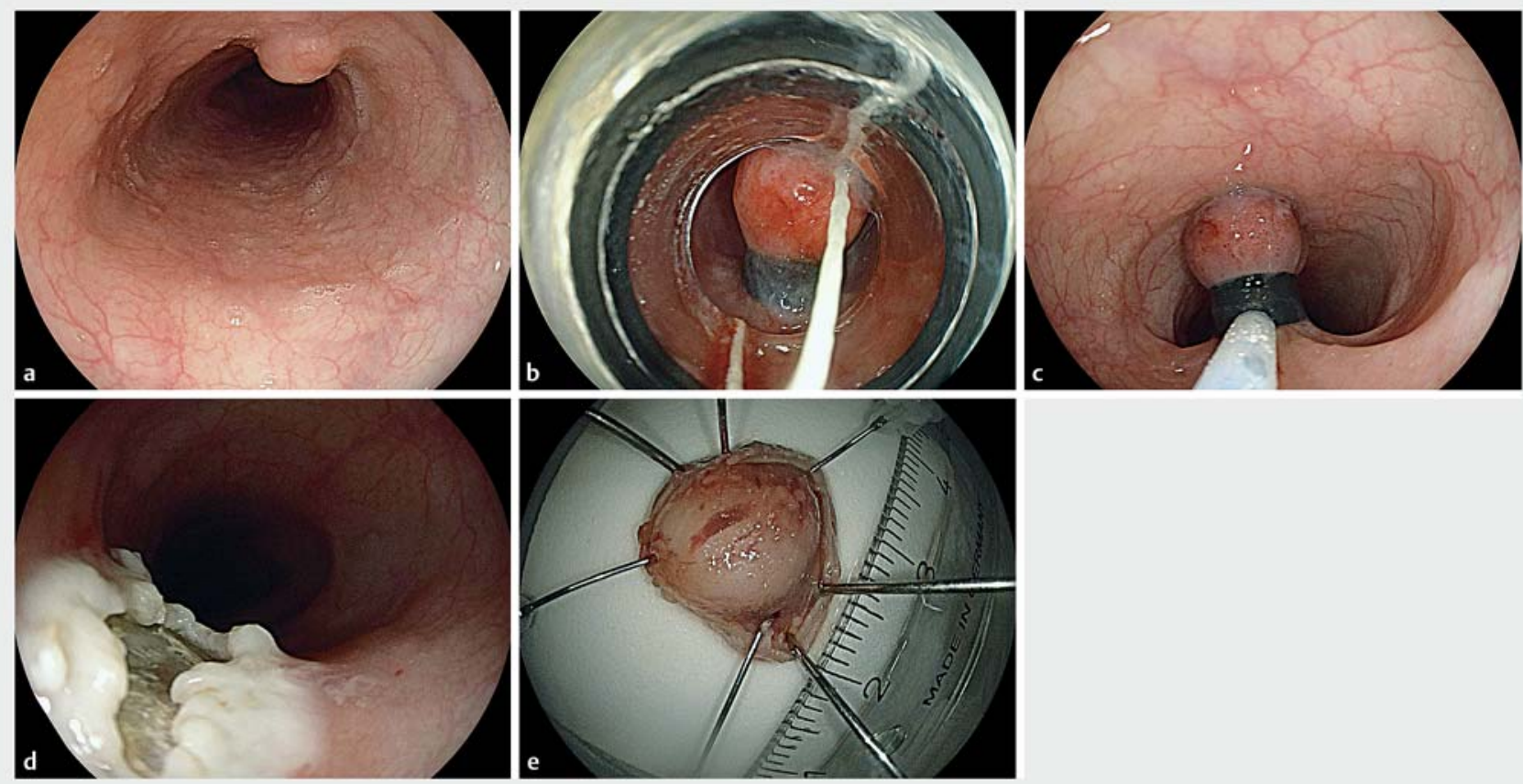

- Fig. 2 Patient 3: a A 9-mm lumen-protruding subepithelial lesion at the 12 o'clock position in the middle esophagus. b After a band ligator device had been mounted (4 Shooter, Saeed Multband Ligator, Cook Medical, Bloomington, USA) and the scope rotated, the lesion was provided with two ligations in one step after suctioning it into the cap. $\mathbf{c}$ The device with the cap was removed, and the lesion was snared by using electrocautery. $\mathbf{d}$ The unremarkable resection bed, without signs of deep mural injury and/or bleeding. e The underside of the resection specimen after retrieval from the stomach with a Roth net (not shown). Note the superficial scraping defect, which was considered to be related to ligation and/or specimen retrieval and untypical for an electrocautery eschar (R0 resection confirmed by pathology).

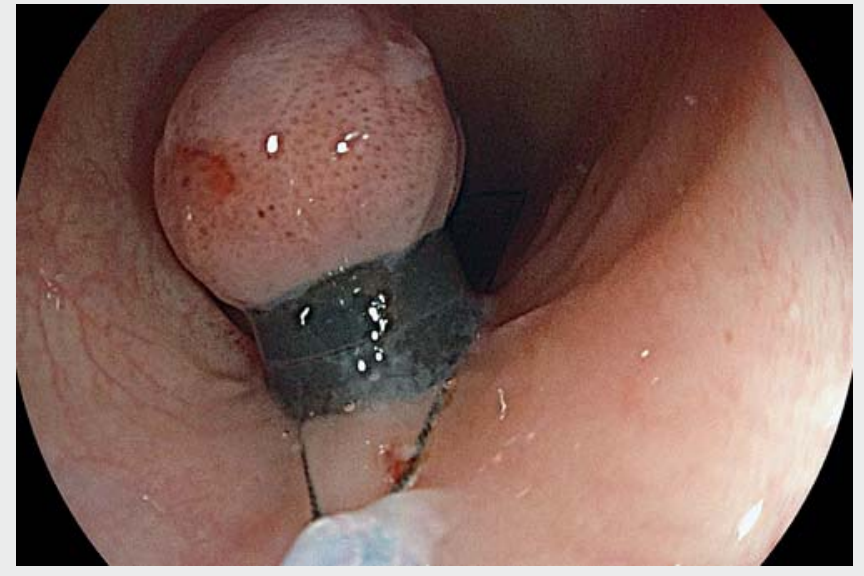

Video 1 The steps of the double ligation-assisted endoscopic submucosal resection (ESMR-DL) procedure in Patient 3.

scopic submucosal resection" (ESMR-DL), for rapid wide-margin removal of small SELs is presented in three consecutive patients [2,3].

- Table 1 and $>$ Fig. 1 illustrate basic patient and SEL characteristics. In addition, variceal ligation (EVL) device is mounted, and the lesion is mobilized and suctioned into the cap. Notably, and unlike most descriptions of ESMR-L, this stage occurs without prior submucosal injection. Next, two bands are placed to increase luminal protuberance and, thus, basal resection margins, and the lesion is released. After removal of the EVL device, the lesion is visualized and snared below the bands using electrocautery. The en bloc specimen may then be retrieved by, for example, a Roth net, and sent for pathological assessment. The intervention is terminated by adequate analysis of the resection bed with or without clipping of the defect.

Endoscopy_UCTN_Code_TTT_1AO_2AG

Competing interests

- Fig. 2 and V Video 1 demonstrate the individual steps of the procedure. In brief, after EUS assessment of echogeneity, vascularity, and, particularly, muscularis propria layer integrity behind the respective lesion, a standard endoscopic 


\section{Vincent Zimmer ${ }^{1,2}$, Bert Bier ${ }^{3}$, Frank} Lammert $^{2}$

1 Department of Medicine, Marienhausklinik St. Josef Kohlhof, Neunkirchen, Germany

2 Department of Medicine II, Saarland University Medical Center, Saarland University, Homburg, Germany

3 Insitute of Pathology Saarbrücken-Rastpfuhl, Saarbrücken, Germany

\section{Corresponding author}

\section{Vincent Zimmer, MD}

Department of Medicine, Marienhausklinik St. Josef Kohlhof, Klinikweg 1-5, 66539

Neunkirchen, Germany

Fax: +49-6821-3632624

vincent.zimmer@gmx.de

\section{References}

[1] Faulx AL, Kothari S. Standards of Practice Committee. et al. The role of endoscopy in subepithelial lesions of the GI tract. Gastrointest Endosc 2017; 85: 1117-1132

[2] Lee DG, Kim GH, Park DY et al. Endoscopic submucosal resection of esophageal subepithelial lesions using band ligation. Endoscopy 2011; 43: 822-825

[3] Choi CW, Kang DH, Kim HW et al. Endoscopic resection for small esophageal submucosa tumor: band ligation versus conventional endoscopic mucosal resection. Medicine (Baltimore) 2017; 96: e7574

\section{Bibliography}

DOI https://doi.org/10.1055/a-0861-9953

Published online: 13.3.2019

Endoscopy 2019; 51: E127-E129

(c) Georg Thieme Verlag KG

Stuttgart · New York

ISSN 0013-726X

\section{ENDOSCOPY E-VIDEOS}

https:/|eref.thieme.de/e-videos

Endoscopy E-Videos is a free access online section, reporting 回: on interesting cases and new techniques in gastroenterological endoscopy. All papers include a high quality video and all contributions are freely accessible online.

This section has its own submission website at

https://mc.manuscriptcentral.com/e-videos 